\title{
Effective utilization of Maker Space for Facilitating Product Realization Course
}

\author{
Satish Chikkamath, Raghavendra Shet ${ }^{2}$, Praveen P, Nalini C. I , B. B Kotturshettar \\ 1,2,3,4,5 KLE Technological University, Vidyanagar Hubballi-580031, INDIA \\ 1chikkamath@kletech.ac.in \\ ${ }^{2}$ raghu@kletech.ac.in \\ 4nalinic@kletech.ac.in
}

\begin{abstract}
Realistic teaching, education learning curriculum and learning setup such as maker's space is very much essential to succeed the impact of Industry 4.0 on industrial engineering (IE). The Makers Space is a state of art facility created to promote product development and realization eco-system in KLE Technological University campus and is administered by the college as a resource for all engineering departments. Design and manufacturing are interdependent process. The curriculum of the verticals present in respective department should address the interdependency. The Makers space provides modern design, prototyping and manufacturing facilities like 3D printer, Laser cutting machine, PCB etching machine which helps to realize any electro mechanical product. The students were made to avail the maker space facility by undergoing a safety training session, the safety session emphasizes on the personal safety in the workshop, safe handling of the equipment. The aim of engineering design and product realization course is to align students to be conversant with the modern manufacturing facility like Makers space and indeed support the students and entrepreneurs to convert their product ideas into
\end{abstract}

\section{Satish Chikkamath}

School of Electronics and Communication Engineering KLE Technological University, Hubbali chikkamath@kletech.ac.in reality. The facilities encourage student teams, faculty members and entrepreneurs working towards creating products to realize our national dream -Make in India

Keywords: Prototyping, make in India, Makers space

\section{Introduction}

In order to sustain the growth of human needs and to sustain in competitive market industry uses high end technology to upgrade the quality in design and manufacturing. To take the advantage of these high end technologies industry demands a skilled and quality engineering graduate, however recent research specifies the need for a teaching curriculum to meet the above stated objective. The need of an hour is design the curriculum by looking into the recent trends in technology and also to use the infrastrue to give more hands on experience.

Creativity, communication, and team work skills are critical to business success, when engineering graduates fails to meet these skills they may lose out a huge opportunity to work in industry. Many engineering students are visual learners they learn better with graphs, maps and diagrams.

The aim of providing a better educational experience can be realized with the concept of maker's space. Learning in Makers space enables learning based on modern practices and facilities for the realization of industrial products. Maker's space helps 
to build a bridge between academia and industry and makes a way to manage with modern industry world [2].

It is necessary to make students to understand the dynamics of changing technology, to make students appreciate technology academia should update the curriculum timely and create a space for hands on experience [7]. Maker's space is an effort to complement the knowledge of emerging modern industry [2], Therefore, it is necessary to design a learning factory where information from industry can be exchanged with academia. This in turn boosts the confidence of an emerging engineering graduate to go out and work.

\section{Makers Space at KLE Tech. University}

The KLE Technological University have a Makers Space on it campus, a specially established state-of-the-art comprehensive manufacturing facility and demonstrate the working of prototype to promote product development and realization ecosystem and is administered by the college as a resource for all engineering departments.

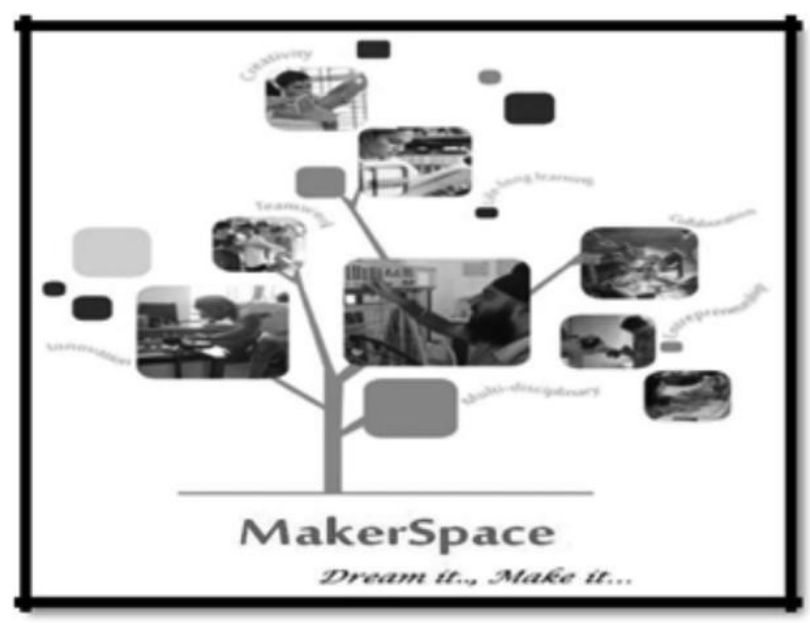

Fig.1: Makers Space

Makers space focus on interdisciplinary work culture catering to technology product design and realization. It facilitates as single platform for different discipline like.

- Mechanical Engineering:

- Electronics Engineering

- Automotive Engineering
Due to speedy change in manufacturing technology and production systems, industry expects students should to be taught and trained with such manufacturing process which helps them to learn and adopt to the changing trends in technology [12]

In order to address variety of potential problems KLE Tech. University has brought the real factory into the classroom. This environment is enough flexible to adopt the challenges in design and manufacturing. Makers Space is a combination of four well defined elements:

- Assembly process

- Assembly product

- Assembly infrastructure

- Teaching methods and approach.

The frame work for Maker Space is as shown below:

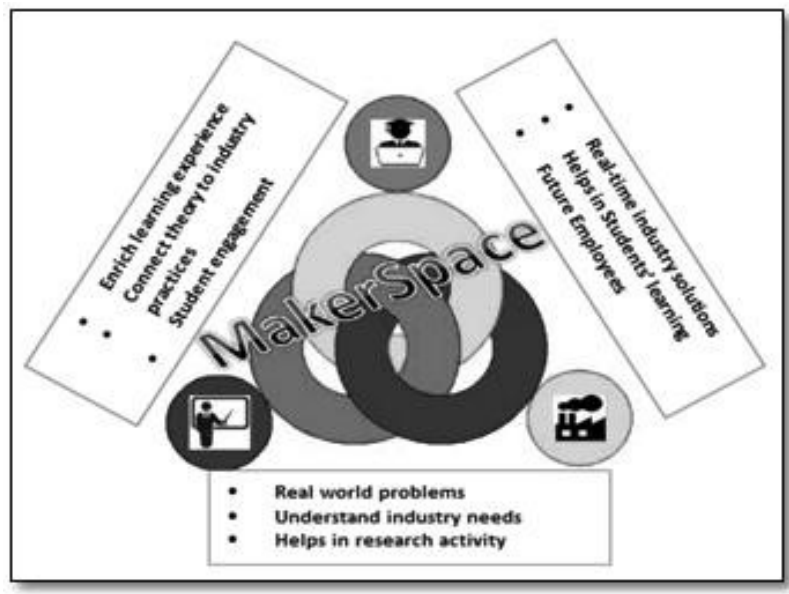

Fig. 2: Machines Makers Space

\section{Product Realization}

\section{Course Introduction}

The Product Realization (PR) encompasses the entire cycle of production, from initial conceptual design to the finished manufacture of product. Key elements of the PR have been studied from both academic and industrial viewpoints.

As an extension to the 'Engineering Design another course 'Product Realization' has been a 2 credit course introduced at the 4th semester. During this course, the emphasis is on the concurrent and collaborative 


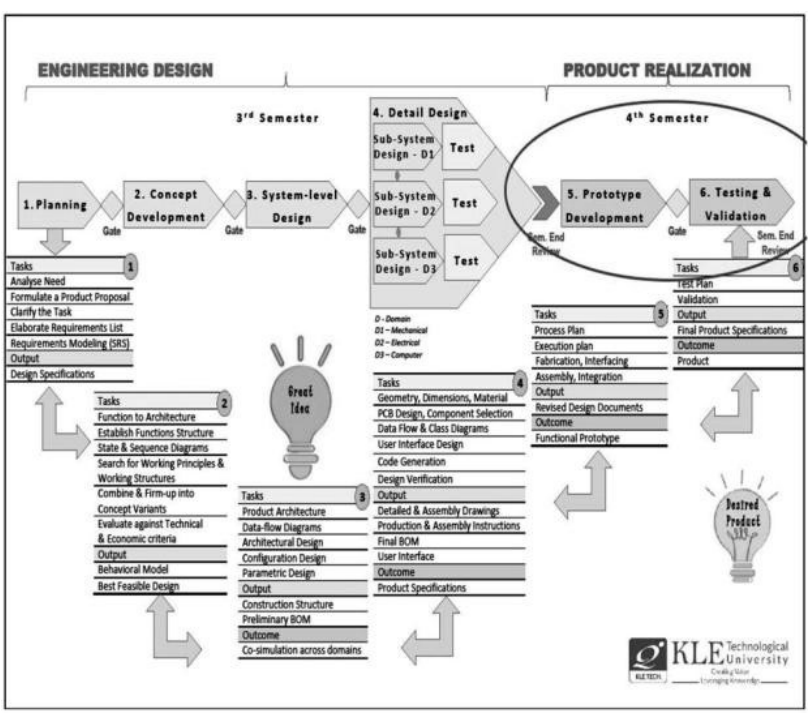

Fig. 3: EDPR Course Structure

process of arriving at the best solutions at each step in the hardware and software development processes and assuring that the total process is optimized with the best of knowledge and tools. At the end of this course, the student teams who have already executed a virtual prototype in the previous semester are required to build in Maker Space.

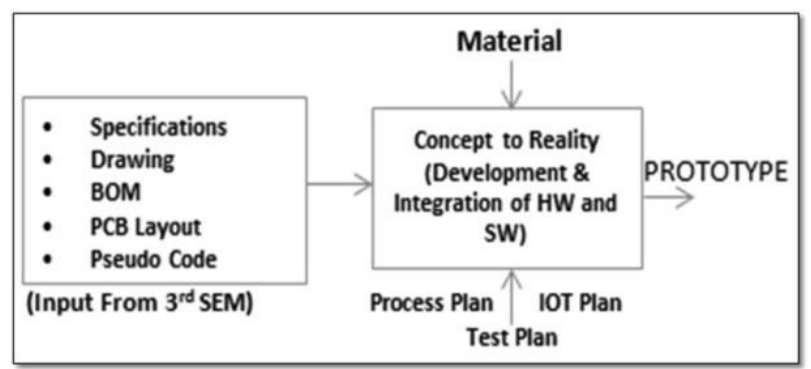

Fig. 4: Product Realization Course Structure

The two courses together provide multi-disciplinary, systems-perspective to problem solving. These two courses enables students to understand the entire product development process, i.e., students are made to realize their ideas into products, and also make them to understand the interdependencies that lie in a multidisciplinary environment

The students who undergo these courses can easily learn the essential skills required to solve real world problems . The key takeaway from these courses for the young designers would be to provide an orderly process for solving an ill-structured design activity. The course includes 5 phases of design process, the taught process that student undergoes in these 5 phases will help him/her to make decisions among possible multiple solutions.

The Maker Space is administered by the College as a resource for all engineering departments. Facilities, with an investment of about 3.0 crores of rupees, occupying 10,000 square feet, include a machine shop (4000sq.ft), model shop (2000sq.ft) and project work area (4000sq.ft). Engineering student can use the Maker Space for concept design \& realization, courserelated activity and/or competition projects such as SAE Formula, SAE- BAJA SAE- Ecokart, SAEEfficycle, ROBOCON, etc.

\section{Implementation}

In Continuation with Engineering Design course at 3rd semester offered to Mechanical, Electrical and Computer Science domain students, Product Realization is continued at 4th semester to offer product development experience in an interdisciplinary environment. This is an attempt probably first of its kind in the engineering education scenario at a large scale. It is a 2 credit course which will engage students from converting the design process done at 3rd semester to design the final product and virtual prototyping.

The sessions are conducted in two parts. Part-I is offered as safety session which is covered in

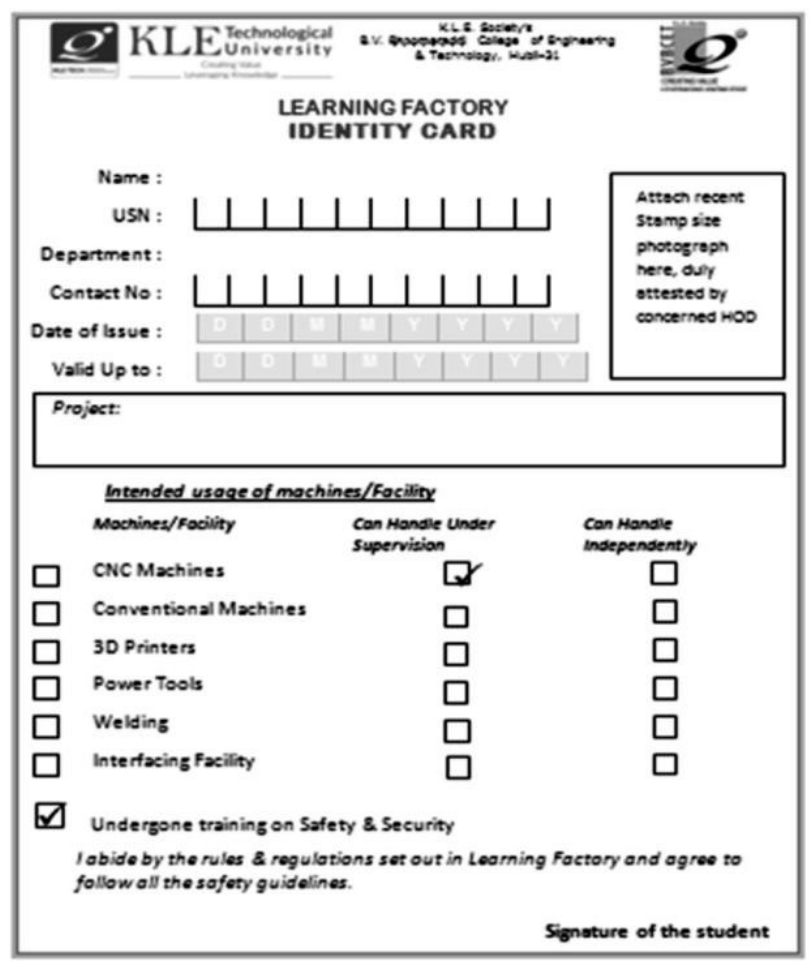


Important Instructions:

- This IDENTITY CARD is the GATE PASS for entry in the Learning Factory \& must be worn on person at all times and is not transferable.

- Usage of MOBILE PHONES during work inside the Learning Factory is strictly prohibited.

- Kindly avail the safety gears/items like heimets, goggles, gioves, ear plugs etc, from Tool Crib Store before the start of work at Learning Factory.

- The workshop safety guidelines must be read before any work is carried out in the Learning Factory.

- A machine tool specific induction must take place before any equipment is used.

- Learning Factory is strictiy a "NO SMOKING ZONE"

- After-hours access to the workshop is NOT PERMITTED without prior approval by the concerned authority.

- In case of emergency contact e. g Fire, Accident inform security or call:

Praveenkumar M Petkar.

Fooivity coorainoto

S N Kulkaoni.

$+919964476030$

$+919739235383$

Note: Induction program on Training for handling tools \& equipment and Sofety" will be canducted on Every Soturday from 10:30am to 12:00noon

\section{Fig. 5: Makers Space Entry ID}

classrooms. These sessions very extensively conducted for each and every student to ensure the safety of the student, staff, and the machine on which he/she working. Theses instructions were followed in Part II on regular session basis for each individual with valid entry ID

In Part II students were allowed to access Makers Space facilities for prototyping their product. There were 15 divisions with 70 students in each division consisting of 1080 students all put together from Mechanical, Electronics \& Communication, Compute Science, Automation \& Robotics and Electrical \& Electronics Engineering disciplines. The sessions and space allotment was scheduled as shown below.

Table 1: Division wise allotment

\begin{tabular}{|c|c|c|c|}
\hline Day & $8: 00-11: 00$ & $11: 15-02: 15$ & $02: 30-05: 30$ \\
\hline Monday & Div 1 & Div 2 & Div 3 \\
\hline Tuesday & Div 4 & Div 5 & Div 6 \\
\hline Wednesday & Div 7 & Div 8 & Div 9 \\
\hline Thursday & Div 10 & Div 11 & Div 12 \\
\hline Friday & Div 13 & Div 14 & Div 15 \\
\hline Saturday & & & \\
\hline
\end{tabular}

Table 2 : Facilities in Nutshell

\begin{tabular}{|l|l|}
\hline \multicolumn{2}{|c|}{ Facilities available in Makers Space } \\
\hline CNC Turning Centre & 3D Printing Machine \\
\hline $\begin{array}{l}\text { CNC Vertical Machining } \\
\text { Centre }\end{array}$ & 3D Imager \\
\hline CNC Wire EDM Machine & $\begin{array}{l}\text { Portable Co-ordinate } \\
\text { Measuring Machine }\end{array}$ \\
\hline
\end{tabular}

\begin{tabular}{|l|l|}
\hline CNC Router & $\begin{array}{l}\text { Plastic Injection } \\
\text { Moulding Machine }\end{array}$ \\
\hline CNC Laser Cutting Machine & $\begin{array}{l}\text { Universal Cylindrical } \\
\text { Grinding Machine }\end{array}$ \\
\hline $\begin{array}{l}\text { CNC Plasma Cutting } \\
\text { Machine }\end{array}$ & $\begin{array}{l}\text { Universal Tool \& Cutter } \\
\text { Grinding Machine }\end{array}$ \\
\hline $\begin{array}{l}\text { 3D Desktop Milling } \\
\text { Machine }\end{array}$ & PCB Machining \\
\hline
\end{tabular}

\section{Prototypes}

With the session schedule followed with various templates for Mechanical, Electrical and Computers, product realization work was initiated and followed up with faculty group allotted for the respective sessions.

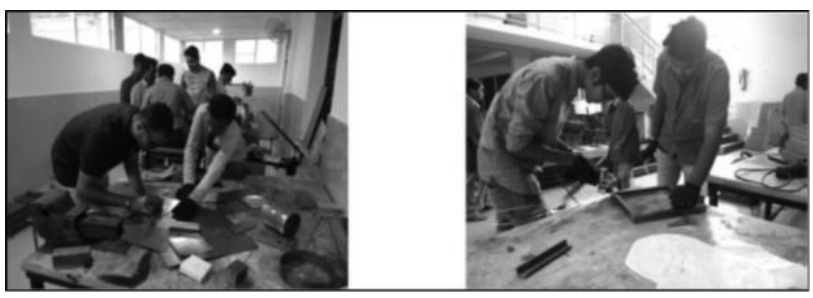

Fig. 6: Mechanical students at work

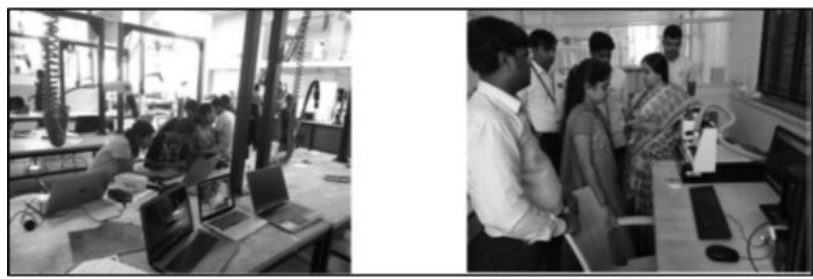

Fig.7: Electronics and computer science students at work

Case Study: Design a device to assist the blind person to walk around, navigate through the places and to provide a monitoring system for the guardian of the user [10].

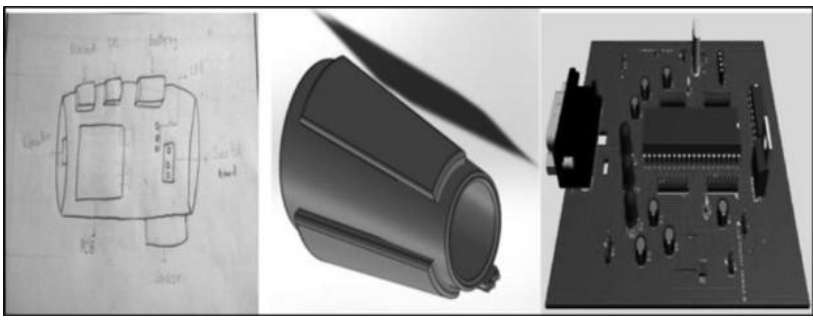

Proposed and 3D model of prototype

Products

The following products are designed and manufactured by students by utilizing the facilities available in makers space. 


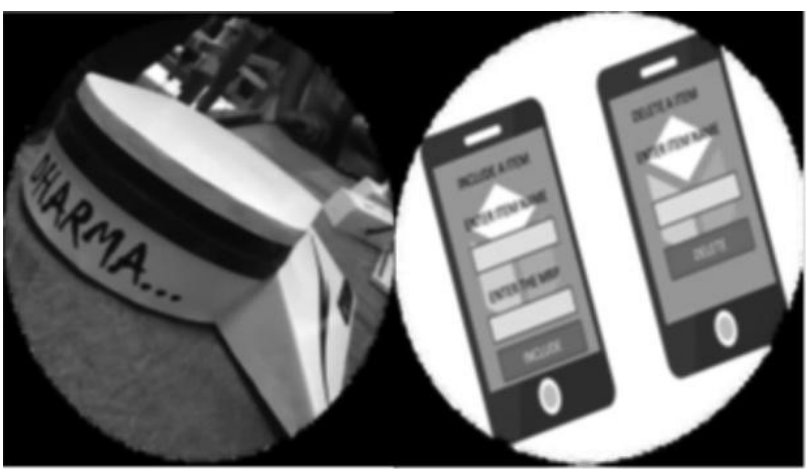

Fig. 8: Weighing and billing machine

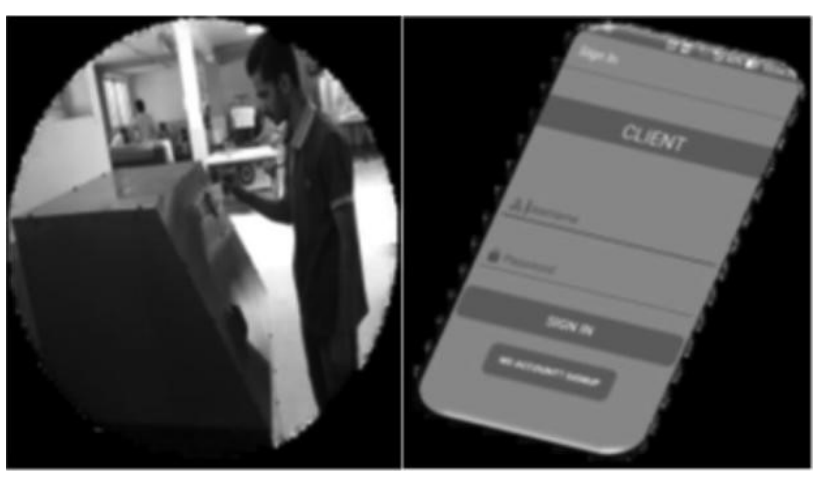

Fig. 9: Can Crusher

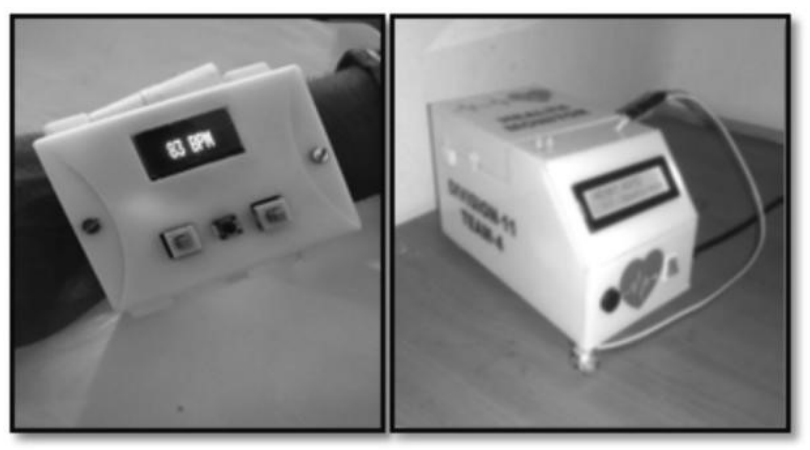

Fig. 10: Health Monitoring Device

\section{Conclusion}

The Makers Space serves a simulative learning environment to strengthen student's professional and social competences, it serves as innovative platform and brings the common understanding between engineering education and business reality. This model of teaching helps students to practice and realize the product work cycle before entering the actual work life

The maker's space is used with success both for teaching and research activities. It also enables practitioners to utilize the facilities and understand the product life cycle, the design of this course enables students to make products and understand the business reality. This design helps to bridge the gap between industry and academia and improve their competences.

\section{References}

[1] John S. Lamancusa, Jens E. Jorgensen, Jose L. Zayas-Castro, Julie Ratner - The Learning Factory - A new approach to integrating design and manufacturing into engineering curriculall -1995 ASEE Conference Proceedings June 2528, 1995

[2] R C Putra, I H Kusumah, M Komaro, Y Rahayu, E P Asfiyanur -Design Learning of Teaching Factory in Mechanical Engineering\| IOP Conf. Series: Materials Science and Engineering 306 ( 2018 ) $012104 \mathrm{doi}: 10.1088 / 175$ 7 - 899X/306/1/012104

[3] Rentzos L A, et al . 2014 Integrating Manufacturing Education with Industrial Practice using Teaching Factory Paradigm: A Construction Equipment Application Procedia CIRP 17 pp $189-194$.

[4] Dimitris M, et al. 2017 A Web-based Application for Classifying Teaching and Learning Factories 7th Conference on Learning Factories, CLF 2017: Procedia Manufacturing 9 pp. $222-228$.

[5] John S L, et al. 1997 The Learning Factory-A New Approach to Integrating Design and Manufacturing into the Engineering Curriculum Journal of Engineering Education

[6] The Making of an Engineer - An illustrated history of engineering education in the United States and Canada, Lawrence Grayson, John Wiley and Sons, 1993.

[7] S. Chikkamath, N. Vannal, R. M. Shet, P. C. Nissimgoudar and N. C. Iyer, "Experiential Learning: Learning through Projects," 2016 IEEE 4th International Conference on MOOCs, Innovation and Technology in Education (MITE), Madurai, 2016, pp. 251-257. Doi: 10.1109/MITE.2016.057

[8] Learning and Teaching Styles in Engineering Education, R.M. Felder, L.K.Silverman; Engineering Education 78(7), April 1988, pp 674-681. 
[9] Cognitive Aspects of Learning and Teaching Science, Jose P. Mestre, Pre-College Teacher Enhancement in Science and Mathematics: Status, Issues and Problems, S. J. Fitzsimmons and L.C. Kerpelman (Eds.), Washington DC: NSF

[10] R. M. Shet, N. C. Iyer, P. C. Nissimgoudar, S. Ajit, "Integrated Experience: Through Project based Learning", Proceedings of the International Conference on Transformations in Engineering Education, Springer, New Delhi, Pg 479-486, Online ISBN: 978-81-322-1931-6

[11] Matt, Dominik T., Erwin Rauch, and PatrickDallasega. "Mini-factory - A Learning Factory Concept for Students and Small and Medium Sized Enterprises", Procedia CIRP. 